OPEN ACCESS

Edited by:

Selena Ahmed

Montana State University,

United States

Reviewed by:

Youssef Aboussaleh,

Ibn Tofail University, Morocco

Aida Turrini,

Council for Agricultural and

Economics Research, Italy

Rekia Belahsen,

Université Chouaib Doukkali, Morocco

*Correspondence:

Sergiy M. Smetana

s.smetana@dil-ev.de

Specialty section

This article was submitted to Nutrition and Environmental

Sustainability,

a section of the journal

Frontiers in Nutrition

Received: 11 December 2018

Accepted: 18 March 2019

Published: 12 April 2019

Citation:

Smetana SM, Bornkessel S and Heinz V (2019) A Path From

Sustainable Nutrition to Nutritional

Sustainability of Complex Food

Systems. Front. Nutr. 6:39

doi: 10.3389/fnut.2019.00039

\section{A Path From Sustainable Nutrition to Nutritional Sustainability of Complex Food Systems}

\author{
Sergiy M. Smetana ${ }^{1 *}$, Sabine Bornkessel ${ }^{1,2}$ and Volker Heinz ${ }^{1}$ \\ ${ }^{1}$ German Institute of Food Technologies (DIL e.V.), Quakenbrück, Germany, ${ }^{2}$ Faculty of Agricultural Sciences and Landscape \\ Architecture, University of Applied Sciences, Osnabrück, Germany
}

Integration of nutritional and sustainable aspects is a complex task tackled by a few scientific concepts. They include multiple dimensions and functions of food systems trying to provide solutions for harmonic co-evolution of humanity and planet Earth. "Nutritional Sustainability" is differentiated from other concepts which combine nutrition and sustainability as it not only sets environmental sustaining capacity as a baseline level for balanced nutrition, but also aims for the search of food system driving nodes. It does not aim for the support of solutions of producing enough or more food for increasing population (sustainable nutrition), neither does it contradict other similar concepts [sustainable nutrition security, nutritional life cycle assessment (LCA)]. However, it calls for more definite estimation of the carrying capacity of the environment on personal, local, and national levels for the development of more efficient solutions of nutrition balanced in the limits of environmental carrying capacity. The review is providing a few examples of advances in nutritional science (personalized nutrition, nutrigenetics), food technology (personalized food processing, food ecodesign), and food complex systems (artificial intelligence and gut microbiome), which have a great potential to progress sustainable food systems with Nutritional Sustainability set as a guiding concept.

Keywords: nutritional sustainability, artificial intelligence, LCA, food ecodesign, personalized diet, complex food systems

\section{INTRODUCTION: FEEDING THE WORLD POPULATION SUSTAINABLY}

Food systems, defined as compositions of interlinked elements and activities aimed for the production, processing, distribution, and consumption of food (1), have been considered to include sustainability aspects for a long time (2). The appearance of sustainability concepts (3) rather quickly and seamlessly transferred to the nutrition research (4) forming the field of Sustainable Nutrition Security $(5,6)$. During the last few decades an increasing number of studies and industrial applications address the topics of supplying more proteins, carbohydrates and energy (4) to feed the increasing population mainly by means of intensive agriculture. Sustainable nutrition, therefore, included research on topics supplying enough resources to grow feed and food for current state and future generations (7); searching efficient solutions to deal with malnutrition (producing more from less) (8) and finding ways for more balanced nutrition and dealing with obesity (producing less from more) (9). 
Nutritional science developed a sophisticated knowledge base on balanced diets (10), which are aimed to promote healthier state of human organisms. "Sustainable diets" approach on the other hand from the initial appearance additionally included avoidance of excessive use and degradation of natural resources (11). Further development of "sustainable diet" approach resulted in inclusion of three main components (social, economic, and environmental) and eventually bigger number of elements each representing a complex system $(12,13)$. Increased complexity in nutritional and sustainability research and need to account for multiple aspects led to the development of two main approaches: First is indicator-based accounting for the key parameters for the development of a universal sustainable diet (1) and second is accounting for the hidden interdependencies with a complex system analysis $(14,15)$.

At the same time, behavioral attitude of people is not always following the recommendation for healthy or sustainable diets (16). Recent studies on the personalization of nutrition based on phenotypic or genotypic information demonstrate the lack of evidence on behavioral changes toward the recommendations (17-19). Similarly, a lack of evidence exists for the demonstration of behavioral change of consumers toward less environmentally impacting foods. Sustainability of food products is at the bottom of the list of important criteria when buying foods in supermarkets (20). Therefore, the lack of evidence on the effect of dietary and sustainability recommendations indicate that there is a need for new leverages for the enhancement of social behavior and societal transition to healthier and more sustainable food consumption.

Absence of efficient means to change the behavior of consumers in developed countries toward healthier and environmentally friendly diets implies the persistence of high rates of food consumption in the future. Statistical data indicate that in Western countries there are higher consumption rates per capita of food rich in simple carbohydrates and fats (21). It leads to the overwhelmed rates of obesity and overweight (Figure 1), which cannot be related to the overall educational or awareness levels of society, but rather to education inequalities within countries $(22,23)$. The overconsumption behavior of Western populations might be a consequence of potentially misleading approach of nutrition security (24) or "Sustainable Nutrition," when the need to supply more foods at lower price results in nutritional shift toward processed foods and convenience products.

It became obvious that existing ways to deal with more sustainable ways to supply adequate amounts of food to growing population cannot be fulfilled in the limits of resources of planet Earth. "Business as usual" approach in nutrition leads to consumption of resources beyond safe planetary boundaries (25). Regional diversity of socio-economic and resource availability conditions further complicates "safe operating boundaries" $(26,27)$. High-income countries have high impacts on the environment associated with high food waste generation at consumer level and with health-impacting nutrient consumption (28). Low-income countries, on the other hand, have higher impacting problems associated with harvesting food losses, food availability and affordability, safety and socio-cultural well-being
(29). Indicated problems call for system solutions, when not only separate technological or societal issues are changed, but also a considerable improvement in the whole system is achieved. Food systems, therefore, are perceived as social-ecological systems, formed of biophysical and social factors linked through feedback mechanisms comprising the activities involved in food production, processing, packaging, distribution, retail, and consumption at different scales (social, economic, political, institutional and environmental processes, and dimensions) (15, $30,31)$. Only considering the multiple elements and connections at different scales it is possible to account for indirect and rebound effects in system solutions. Currently, there are a few conceptual approaches suggested as a basis for the system change: socio-technical regimes and sustainability transitions $(32,33)$, resilience of systems and sustainability transformations (34), "Sustainable Nutrition Security" as multiscale multidimension policy-oriented methodology $(6,35)$. At the same time, "sustainable diet" or "healthy diet" approaches set as a guiding principle for sustainable food systems are not fulfilling the criteria of complex system transformation (36), and therefore are not calling for efficient transformation of the entire food system, but rather for niche solutions.

In this paper, the main studies exploring connections between "nutrition" and "environmental impact" with different approaches will be overviewed. We performed a literature search in open literature databases and search engines of "Google Scholar," "Mendeley" and "WorldWideScience" in 2018, beginning 2019 using the terms "nutrition," "environmental impact," "Life Cycle Assessment," "food system," "complex system," “complex system control," "sustainable nutrition," "sustainable diet." The search aimed for original studies, case studies, reviews, or highlights pointing at the connection between nutrition, human health and environment and emerging solutions allowing the transformation of complex food systems. The references of the articles found were also explored for consistency. The findings highlighting the potential for transformation of complex food systems will be discussed.

\section{HEALTHY POPULATION AND THE ENVIRONMENT}

Emergence of Life Cycle Assessment (LCA) in food field supported the statements of finding ways for more efficient production to feed future growing population. However, recent studies concentrate more and more on the need to combine indirect food impact (environmental impact with LCA) with direct impact of food (allergies, toxins, nutrition). They concentrate on the need to reveal the direct food impact (nutritional properties) as a form of environmental influence. Nutritional studies, at the same time, start concentrating on issues of balanced diet for healthy population and "low" nutrition diets (sugar, carbohydrates, fat, or calories) for groups with special dietary requirements (overweight, obese). This way, two separate concepts originating from LCA of food and nutrition: (1) dealing with direct and indirect environmental impacts; and (2) (re-)balanced nutritional diets are leading 


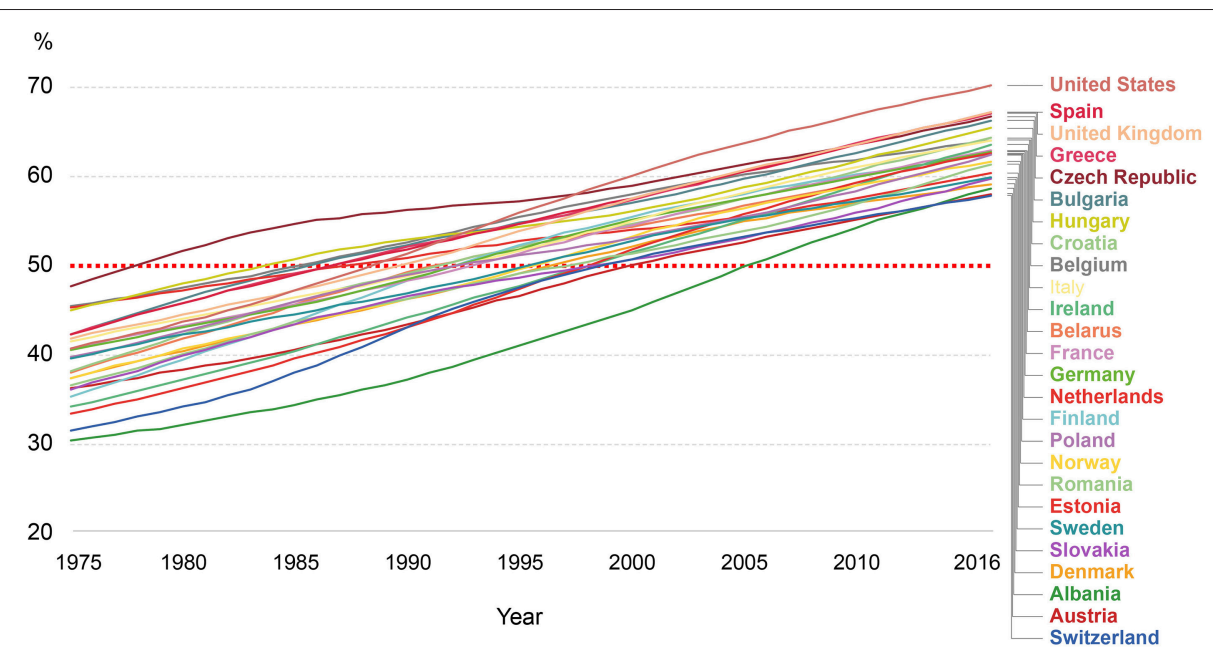

FIGURE 1 | Share of adult population in some Western countries (18 years and more) who have a body-mass index (BMI) $\geq 25$ (adapted from ourworldindata.org, based on data from WHO, Global Health Observatory).

to the change of perception from "Sustainable Nutrition" to "Nutritional Sustainability." A very useful definition of Nutritional Sustainability is offered by Swanson et al. (37): "Nutritional sustainability is the ability of a food system to provide sufficient energy and the amounts of essential nutrients required to maintain good health of the population without compromising the ability of future generations to meet their nutritional needs." It is interesting that innovations related to nutritional sustainability are often associated with product development in the pet food industry, which is more inclined to use alternative biomass sources and by-products from "human food system" (37-40).

Most of the studies, dealing with sustainability and nutrition, even though point out to that need to approach the food system holistically $(1,13,14,29,41-43)$, rarely relate to the findings of complex system analysis and complex system control theories $(36,44)$, thus suggesting niche solutions, not able to transform the entire system. That is why, we considered further development of "Nutritional Sustainability" highlighting potential paths for food system change. Nutritional sustainability is an ability of human communities [as key driving nodes (36)] to find ways of complex food system transformation toward limited consumption of natural resources within regional or planetary boundaries while fulfilling own nutritional needs. The definition includes a few main components: human communities (groups, populations) as elements with highest degree of distribution (36), boundaries outlining the transformation aim of complex food system in current state and in the future and multiscale approach (from regional to global). Nutritional sustainability, therefore, allows to concentrate on defining specific nodes on each level, capable of guiding the dynamics of the whole complex system.

Emergence of "Nutritional Sustainability" is seamlessly changing the future scope of nutritional science, LCA of food and potentially resulting in formation of a new joined concept field. There are a few signs, which indicate the formation of a new area of sustainability research. Several recent studies aiming for the assessment of nutrition and diets rely on more complex nutritional basis (comparing to previously used mass, energy, or protein content-based units). Researchers emphasize on the need to account the consumption of right amount of food for the establishment of healthy diets $(42,43,45)$. Others put efforts for the development of methodologies for the combination of environmental and direct food impacts on health $(41,46)$ or target wide scope of sustainable indicators related to food production and consumption $(5,29)$. Such trends identify the need for the combination of knowledge on joined environmental and direct social effects with efficient communication and nudging approaches to force the behavioral change.

A fair question from the reader would be on importance of conceptual change from "Sustainable Nutrition" and "Sustainable Nutrition Security" $(6,12)$ to "Nutritional Sustainability." What changes might the emergence of "Nutritional Sustainability" bring in the future for the research, industries, and society? We believe that such a conceptual shift in thinking is associated with the need to define specific action nodes with high degree of influence (driver nodes) capable of system transformation to a new state with defined boundaries. Currently, the most adequate system boundaries of safe human operations are outlined with the concept of planetary boundaries (26). More radical concepts of sustainability are currently required, as existing "soft" and "gradual" approaches are not able to coop with rapidly evolving environmental problems $(47,48)$. For example, research activities aiming for more radical solutions could be "blocked" by the legal and ethical established practices. Even though, the General Data Protection Regulation (49), which got in force in 2018, is aimed to protect human rights for safety of personal information, it creates multiple obstacles for the clinical and nutrition related research activities in EU. Even though it does not directly block the use of bibliometric, health and genetic related data for research purposes, it creates multiple challenges and obstacles in working with such data (50-52). Moreover, raised ethical issues on the influence of digital marketing create ethical limitations on the use 
of data from social and digital networks (53). Legal obstacles also exist in terms of nutritional human research related to novel food sources such as insects and microalgae (54-57). These are only a few of the limiting examples for the acceptance of Nutritional Sustainability as a guiding concept for the research and practice in food systems.

\section{SHIFTING COMPLEX FOOD SYSTEM TO THE DESIRED STATE}

The concept of Nutritional Sustainability can also be beneficial for recent research activities in multiple fields. Personalization of nutrition as a potential driving node of a complex system is already foreseen as one the most important topics to solve problems associated with elderly nutrition (aging population in Western countries) and special dietary needs (allergies, intolerances, overweight, and malnutrition), which is reflected in increasing number of studies (58). Moreover, personalized adapted food production (e.g., reformulation) or "personalized food processing" (e.g., additive manufacture) could result in more resource efficient food production with reduced amount of food wasted (59). Determination of specific dietary requirements based on nutrigenomic and nutrigenetic data $(60,61)$ and current state of an organism in combination with precise fulfillment of such needs could potentially lead to more balanced and healthy nutrition with minimized environmental impact.

Another emerging approach connected with the concept of Nutritional Sustainability is transferring from industrial ecology. Ecodesign of food can be a viable conceptual methodology, when used not only from the perspective of using less resources to produce food, but also in terms of designing potential food reuse or recycle. It is well-recognized that LCA is more effective as a tool if applied at the stage of design. Despite some rare examples (62), ecodesign is not applied in food industry, due to the absence of data on the future production and consumption processes of a developed product. Moreover, food products are developed with safety, nutritional properties, shelf stability in mind, but almost never with potential for recycling or upcycling. The design phase is currently not accounting for the need to separate packaging, components of meals, and disintegrate biomass for further use. Ecodesign of food (not only food technologies) has a potential of transformation of food waste management. Therefore, food waste treatment is becoming a complex technologically intensive problem, which could be solved at the beginning of the chain with integration of ecodesign principles in food product development (as a key driving node capable of shifting complex system). Integration of ecodesign principles in the upstream stages of food production could lead to more efficient food waste treatment.

Studies, associated with the topic of nutrition and sustainability, more often indicate the upcoming influence of artificial intelligence methods $(63,64)$. The developments are not limited to the identification of properties, but also oriented toward the analysis of dynamic health effects, often acquired with multiple personal health tracking devices appearing on the market. Emergence of nutrigenomics and identification of connections between genetic preconditions and food impact on health through machine learning techniques (61) is giving a new boost for the development of nutritional sustainability. Such approach can result in supplying defined amount of personally tailored food and in lowering of environmental impact (resource and waste reduction).

Furthermore, direct impact of food on health is correlated with human gut microbiome. It is well-known that microbiome is in a great degree defining the health of a human organism. Healthy functioning of gut microbiome from one side depends on the diet and from the other supports proper functioning of metabolism and nutrition, physiology and immune system. Unbalanced gut microbiome can cause severe gastrointestinal conditions such as inflammatory bowel disease and irritable bowel syndrome, and further force development of obesity, type 2 diabetes, and atopy (65). Recent studies indicate that pre-biotics might not be as suitable for the reinforcement of microbiome in all the cases as previously believed (66). It is also well-known that food and diets affect different people in diverse ways. Multiple other studies indicate that gut microbiome might be structured and function differently under different conditions, which call for studies on complex system analysis, e.g., multiomics and time series measurements (67). A great diversity of functions, compositions of gut microbes and human personalized attributes create a necessity to find a viable approach applicable for the analysis of their interference as a complex system (68). Machine learning and artificial intelligence algorithms can analyze complex systems of gut microbiome and human health personalized responses in real time and provide applicable recommendations (63). Complex multilayer interaction between food consumed, gut microbiome, health effects, and current advances achieved with application of artificial intelligence indicate the emergence of another driving node for transition of food systems.

The complexity of food-human-sustainability interaction is connected not only to multiple components, but also to the rapid expansion of the system. Human health is a category of direct impact of nutrients and environment, but not limited to those components. Social components of health care, life style, culture and traditions (to name a few) as complex systems themselves substantially complicate the food system. Then the estimation of safe operating boundaries of different scales requires not only smart artificial intelligence algorithms, but also a proper modeling of complex systems $(36,64)$, dynamic multilayer networks (69), and ecodesign principles.

\section{OUTLOOK}

Nutritional Sustainability is differentiated from other concepts combining nutrition and sustainability via setting environmental sustaining capacity as aiming point, achievable via changing of key driving nodes for transformation of food systems. Current advances in nutritional science, food technologies, and complex food systems indicate that such a concept is emerging in the nearest future. Nutritional Sustainability concept does not contradict to other similar concepts (sustainable nutrition security, nutritional LCA), but it calls for more definite 
estimation of the carrying capacity of the environment on personal, local, and national levels and identification of key driving nodes able guiding the dynamics of entire system. Without such system boundaries and key driving nodes, theoretical and practical solutions would be limited in efficiency.

\section{AUTHOR CONTRIBUTIONS}

SS, SB, VH contributed equally to conception and design of the study. SS and SB performed literature review. SS wrote the

\section{REFERENCES}

1. Willett W, Rockström J, Loken B, Springmann M, Lang T, Vermeulen $\mathrm{S}$, et al. Food in the Anthropocene: the EAT-Lancet Commission on healthy diets from sustainable food systems. Lancet. (2019) 393:447-92. doi: 10.1016/S0140-6736(18)31788-4

2. Christensen C. The right to food: how to guarantee. Alternatives. (1978) 4:181-220. doi: 10.1177/030437547800400202

3. Brundtland GH. Our common future-Call for action. Environmental Conservation. (1987) 14(4):291-4.

4. Burlingame B. Grand challenges in nutrition and environmental sustainability. Front Nutr. (2014) 1:3. doi: 10.3389/fnut.2014.00003

5. Gustafson DI. Assessing sustainable nutrition security: the role of food systems. Agric Dev Notes. (2016) 7:1-2.

6. Gustafson D, Gutman A, Leet W, Drewnowski A, Fanzo J, Ingram J. Seven food system metrics of sustainable nutrition security. Sustainability. (2016) 8:196. doi: 10.3390/su8030196

7. Godfray HCJ, Beddington JR, Crute IR, Haddad L, Lawrence D, Muir JF, et al. Food security: the challenge of feeding 9 billion people. Science. (2010) 327:812-8. doi: 10.1126/science. 1185383

8. Beal T, Massiot E, Arsenault JE, Smith MR, Hijmans RJ. Global trends in dietary micronutrient supplies and estimated prevalence of inadequate intakes. PLoS ONE. (2017) 12:e0175554. doi: 10.1371/journal.pone.0175554

9. Rössner S, Egger G, Binns A, Sagner M. Overweight and obesity. In: Egger $\mathrm{G}$, Binns $\mathrm{A}$, Rössner $\mathrm{S}$, Sagner $\mathrm{M}$, editors. Lifestyle Medicine: Lifestyle, the Environment and Preventive Medicine in Health and Disease. 3rd Edn. London:Academic Press (2017). p. 105-32. doi: 10.1016/B978-0-12-810401-9.00007-3

10. WHO. Nutrition for Health and Development: A Global Agenda for Combating Malnutrition. Geneva: World Health Organization (2000).

11. Gussow JD, Clancy KL. Dietary guidelines for sustainability. J Nutr Educ. (1986) 18:1-5.

12. Jones AD, Hoey L, Blesh J, Miller L, Green A, Shapiro LF. A systematic review of the measurement of sustainable diets. Adv Nutr. (2016) 7:641-64. doi: 10.3945/an.115.011015

13. Donini LM, Dernini S, Lairon D, Serra-Majem L, Amiot M-J, del Balzo V, et al. A consensus proposal for nutritional indicators to assess the sustainability of a healthy diet: the mediterranean diet as a case study. Front Nutr. (2016) 3:37. doi: 10.3389/fnut.2016.00037

14. Reedy J, Krebs-Smith SM, Hammond RA, Hennessy E. Advancing the science of dietary patterns research to leverage a complex systems approach. J Acad Nutr Diet. (2017) 117:1019-22. doi: 10.1016/j.jand.2017.03.008

15. Tendall DM, Joerin J, Kopainsky B, Edwards P, Shreck A, Le QB, et al. Food system resilience: defining the concept. Glob Food Sec. (2015) 6:17-23. doi: 10.1016/j.gfs.2015.08.001

16. Wing RR, Goldstein MG, Acton KJ, Birch LL, Jakicic JM, Sallis JF, et al. Behavioral Science Research in Diabetes: Lifestyle changes related to obesity, eating behavior, and physical activity. Diabetes Care. (2001) 24:117-23. doi: $10.2337 /$ diacare.24.1.117

17. O’Donovan CB, Walsh MC, Gibney MJ, Brennan L, Gibney ER. Knowing your genes: does this impact behaviour change? Proc Nutr Soc. (2017) 76:182-91. doi: $10.1017 /$ S0029665116002949 first draft of the manuscript. SB wrote sections on nutrition of the manuscript. VH provided input in sustainable food system design. All authors contributed to manuscript revision, read, and approved the submitted version.

\section{ACKNOWLEDGMENTS}

The authors acknowledge the support of DIL e.V. (German Institute of Food Technologies) for the implementation of the study.

18. Celis-Morales C, Livingstone KM, Marsaux CFM, Macready AL, Fallaize $\mathrm{R}$, O'Donovan $\mathrm{CB}$, et al. Effect of personalized nutrition on health-related behaviour change: evidence from the Food4me European randomized controlled trial. Int J Epidemiol. (2016) 46:578-88. doi: 10.1093/ije/dyw186

19. Marsaux CF, Celis-Morales C, Livingstone KM, Fallaize R, Kolossa S, Hallmann J, et al. Changes in physical activity following a genetic-based internet-delivered personalized intervention: randomized controlled trial (Food4Me). J Med Internet Res. (2016) 18:e30. doi: 10.2196/jmir.5198

20. Grunert KG, Hieke S, Wills J. Sustainability labels on food products: Consumer motivation, understanding and use. Food Policy. (2014) 44:177-89. doi: 10.1016/j.foodpol.2013.12.001

21. FAO. Food Balance Sheets. (2018). Available online at: http://www.fao.org/ faostat/en/\#data/FBS (accessed November 15, 2018)

22. Roskam A-JR, Kunst AE, Van Oyen H, Demarest S, Klumbiene J, Regidor E, et al. Comparative appraisal of educational inequalities in overweight and obesity among adults in 19 European countries. Int J Epidemiol. (2010) 39:392-404. doi: 10.1093/ije/dyp329

23. Großschädl F, Stronegger WJ. Long-term trends (1973-14) for obesity and educational inequalities among Austrian adults: men in the fast lane. Eur J Public Health. (2019). doi: 10.1093/eurpub/cky280

24. Noack A-L, Pouw NRM. A blind spot in food and nutrition security: where culture and social change shape the local food plate. Agric Hum Values. (2015) 32:169-82. doi: 10.1007/s10460-014-9538-y

25. Rockström J, Steffen W, Noone K, Persson Å, Chapin FS III, Lambin E, et al. Planetary boundaries: exploring the safe operating space for humanity. Ecol Soc. (2009) 14:32. Available online at: http://www.ecologyandsociety.org/ vol14/iss2/art32/

26. Rockström J, Steffen W, Noone K, Persson A, Chapin FS, Lambin EF, et al. A safe operating space for humanity. Nature. (2009) 461:472-5. doi: $10.1038 / 461472$ a

27. Vieux F, Perignon M, Gazan R, Darmon N. Dietary changes needed to improve diet sustainability: are they similar across Europe? Eur J Clin Nutr. (2018) 72:951-960. doi: 10.1038/s41430-017-0080-z

28. Stenmarck Â, Jensen C, Quested T, Moates G, Buksti M, Cseh B, et al. Estimates of European Food Waste Levels. Stockholm: IVL Swedish Environmental Research Institute (2016).

29. Chaudhary A, Gustafson D, Mathys A. Multi-indicator sustainability assessment of global food systems. Nat Commun. (2018) 9:848. doi: 10.1038/s41467-018-03308-7

30. Ericksen PJ. Conceptualizing food systems for global environmental change research. Glob Environ Change. (2008) 18:234-45. doi: 10.1016/j.gloenvcha.2007.09.002

31. Cash D, Adger WN, Berkes F, Garden P, Lebel L, Olsson P, et al. Scale and cross-scale dynamics: governance and information in a multilevel world. Ecol Soc. (2006) 11:8. Available online at: http://www.ecologyandsociety.org/vol11/ iss $2 / \operatorname{art} 8 /$

32. Markard J, Raven R, Truffer B. Sustainability transitions: an emerging field of research and its prospects. Res Policy. (2012) 41:955-67. doi: 10.1016/j.respol.2012.02.013

33. Geels FW. The multi-level perspective on sustainability transitions: Responses to seven criticisms. Environ Innov Soc Transit. (2011) 1:24-40. doi: 10.1016/j.eist.2011.02.002 
34. Olsson P, Galaz V, Boonstra WJ. Sustainability transformations: a resilience perspective. Ecol Soc. (2014) 19:1. doi: 10.5751/ES-06799-190401

35. Acharya T, Fanzo J, Gustafson D, Ingram J, Schneeman B, Allen L, et al. Assessing Sustainable Nutrition Security: The Role of Food Systems. Washington, DC: ILSI Research Foundation; Center for Integrated Modeling of Sustainable Agriculture and Nutrition Security (2014).

36. Liu Y-Y, Barabási A-L. Control principles of complex systems. Rev Mod Phys. (2016) 88:035006. doi: 10.1103/RevModPhys.88.035006

37. Swanson KS, Carter RA, Yount TP, Aretz J, Buff PR. Nutritional sustainability of pet foods. Adv Nutr. (2013) 4:141-50. doi: 10.3945/an.112.003335

38. Bosch G, Zhang S, Oonincx DGAB, Hendriks WH. Protein quality of insects as potential ingredients for dog and cat foods. J Nutr Sci. (2014) 3:e29. doi: $10.1017 /$ jns.2014.23

39. Dossey AT, Tatum JT, McGill WL. Modern insect-based food industry: current status, insect processing technology, and recommendations moving forward. In: Insects as Sustainable Food Ingredients. Elsevier. p. 113-152.

40. Allen SE, Fahey GC, Corbin JE, Pugh JL, Franklin RA. Evaluation of byproduct feedstuffs as dietary ingredients for dogs. J Anim Sci. (1981) 53:1538-44. doi: $10.2527 /$ jas $1982.5361538 \mathrm{x}$

41. Stylianou KS, Heller MC, Fulgoni VL, Ernstoff AS, Keoleian GA, Jolliet O. A life cycle assessment framework combining nutritional and environmental health impacts of diet: a case study on milk. Int J Life Cycle Assess. (2016) 21:734-46. doi: 10.1007/s11367-015-0961-0

42. Hallström E, Davis J, Woodhouse A, Sonesson U. Using dietary quality scores to assess sustainability of food products and human diets: a systematic review. Ecol Indic. (2018) 93:219-30. doi: 10.1016/j.ecolind.2018.04.071

43. Heller MC, Keoleian GA, Willett WC. Toward a life cycle-based, dietlevel framework for food environmental impact and nutritional quality assessment: a critical review. Environ Sci Technol. (2013) 47:12632-47. doi: 10.1021/es4025113

44. Liu Y-Y, Slotine J-J, Barabási A-L. Controllability of complex networks. Nature. (2011) 473:167-73. doi: 10.1038/nature10011

45. Sonesson U, Davis J, Flysjö A, Gustavsson J, Witthöft C. Protein quality as functional unit - A methodological framework for inclusion in life cycle assessment of food. J Clean Prod. (2017) 140:470-8. doi: 10.1016/j.jclepro.2016.06.115

46. Smetana S, Bornkessel S, Aganovic K, Heinz V. Alternative food production systems: from insects and microalgae to emerging processing technologies and smart LCA systems. In: 11th International Conference on Life Cycle Assessment of Food 2018 (LCA Food) in Conjunction With the 6th LCA AgriFood Asia and 7 th International Conference on Green and Sustainable Innovation (ICGSI) On Global Food Challenges Towards Sustainable Consum. Bangkok.

47. Boysen LR, Lucht W, Gerten D, Heck V, Lenton TM, Schellnhuber HJ. The limits to global-warming mitigation by terrestrial carbon removal. Earths Future. (2017) 5:463-74. doi: 10.1002/2016EF000469

48. Honegger M, Reiner D. The political economy of negative emissions technologies: consequences for international policy design. Clim Policy. (2018) 18:306-21. doi: 10.1080/14693062.2017.1413322

49. European Union. Regulation (EU) No 2016/679 of the European Parliament and of the Council of 27 April 2016 the Protection of Natural Persons With Regard to the Processing of Personal Data and on the Free Movement of Such Data, and Repealing Directive 95/46/EC (General Data Protection Regulation). (2016). L 119:1-88.

50. Chassang G. The impact of the EU general data protection regulation on scientific research. Ecancermedicalscience. (2017) 11:709. doi: 10.3332/ecancer.2017.709

51. Negrouk A, Lacombe D. Does GDPR harm or benefit research participants? An EORTC point of view. Lancet Oncol. (2018) 19:1278-80. doi: 10.1016/S1470-2045(18)30620-X

52. Shabani M, Borry P. Rules for processing genetic data for research purposes in view of the new EU General Data Protection Regulation. Eur J Hum Genet. (2018) 26:149-56. doi: 10.1038/s41431-017-0045-7

53. Tatlow-Golden M, Verdoodt V, Oates J, Jewell J, Breda JJ, Boyland E. A safe glimpse within the "black box"? Ethical and legal principles when assessing digital marketing of food and drink to children. WHO Public Heal Panor. (2017) 3:613-21.
54. van der Spiegel M, Noordam MY, van der Fels-Klerx HJ. Safety of novel protein sources (Insects, Microalgae, Seaweed, Duckweed, and Rapeseed) and legislative aspects for their application in food and feed production. Compr Rev Food Sci Food Saf. (2013) 12:662-78. doi: 10.1111/1541-4337. 12032

55. Lähteenmäki-Uutela A, Grmelová N. European law on insects in food and feed. Eur Food Feed Law Rev. (2016) 11:2-8. Available online at: http://www. jstor.org/stable/43958606

56. Vigani M, Parisi C, Rodríguez-Cerezo E, Barbosa MJ, Sijtsma L, Ploeg $\mathrm{M}$, et al. Food and feed products from micro-algae: market opportunities and challenges for the EU. Trends Food Sci Technol. (2015) 42:81-92. doi: 10.1016/j.tifs.2014.12.004

57. Enzing C, Ploeg M, Barbosa M, Sijtsma L. Microalgae-based products for the food and feed sector: an outlook for Europe. JRC Sci Policy Rep. (2014)19-37.

58. de Toro-Martín J, Arsenault B, Després J-P, Vohl M-C. Precision nutrition: a review of personalized nutritional approaches for the prevention and management of metabolic syndrome. Nutrients. (2017) 9:913. doi: $10.3390 /$ nu9080913

59. Walker C, Gibney ER, Hellweg S. Comparison of environmental impact and nutritional quality among a european sample population - findings from the Food4Me study. Sci Rep. (2018) 8:2330. doi: 10.1038/s41598-018-2 0391-4

60. Fenech M, El-Sohemy A, Cahill L, Ferguson LR, French T-AC, Tai ES, et al. Nutrigenetics and nutrigenomics: viewpoints on the current status and applications in nutrition research and practice. J Nutrigenet Nutrigenomics. (2011) 4:69-89. doi: 10.1159/000327772

61. Ordovas JM, Ferguson LR, Tai ES, Mathers JC. Personalised nutrition and health. BMJ. (2018) 361:bmj.k2173. doi: 10.1136/bmj.k2173

62. Espinoza-Orias N, Cooper K, Lariani S. Integrated product development at Nestlé. In: Benetto E, Gericke K, Guiton M. Designing Sustainable Technologies, Products and Policies. Cham: Springer International Publishing (2018). p. 447-456.

63. Zeevi D, Korem T, Zmora N, Israeli D, Rothschild D, Weinberger A, et al. Personalized nutrition by prediction of glycemic responses. Cell. (2015) 163:1079-94. doi: 10.1016/j.cell.2015.11.001

64. Smetana S, Seebold C, Heinz V. Neural network, blockchain, and modular complex system: The evolution of cyber-physical systems for material flow analysis and life cycle assessment. Resour Conserv Recycl. (2018) 133:229-30. doi: 10.1016/j.resconrec.2018.02.020

65. Bull MJ, Plummer NT. Part 1: the human gut microbiome in health and disease. Integr Med A Clin J. (2014) 13:17-22.

66. Zmora N, Zilberman-Schapira G, Suez J, Mor U, Dori-Bachash M, Bashiardes S, et al. Personalized gut mucosal colonization resistance to empiric probiotics is associated with unique host and microbiome features. Cell. (2018) 174:1388-405.e21. doi: 10.1016/j.cell.2018. 08.041

67. Cani PD. Human gut microbiome: hopes, threats and promises. Gut. (2018) 67:1716-25. doi: 10.1136/gutjnl-2018-316723

68. Hadrich D. Microbiome research is becoming the key to better understanding health and nutrition. Front Genet. (2018) 9:212. doi: 10.3389/fgene.2018. 00212

69. Boccaletti S, Bianconi G, Criado R, del Genio CI, Gómez-Gardeñes J, Romance $\mathrm{M}$, et al. The structure and dynamics of multilayer networks. Phys Rep. (2014) 544:1-122. doi: 10.1016/j.physrep.2014.07.001

Conflict of Interest Statement: The authors declare that the research was conducted in the absence of any commercial or financial relationships that could be construed as a potential conflict of interest.

Copyright (c) 2019 Smetana, Bornkessel and Heinz. This is an open-access article distributed under the terms of the Creative Commons Attribution License (CC BY). The use, distribution or reproduction in other forums is permitted, provided the original author(s) and the copyright owner(s) are credited and that the original publication in this journal is cited, in accordance with accepted academic practice. No use, distribution or reproduction is permitted which does not comply with these terms. 